\title{
Efficient Charge Transfer Mechanism in Polyfluorene/ZnO Nanocomposite Thin Films
}

\author{
Bandar Ali Al-Asbahi, ${ }^{1,2}$ Mohammad Hafizuddin Haji Jumali, ${ }^{1}$ and Rashad Al-Gaashani ${ }^{3}$ \\ ${ }^{1}$ School of Applied Physics, Faculty of Science and Technology, Universiti Kebangsaan Malaysia (UKM), 43600 Bangi, \\ Selangor, Malaysia \\ ${ }^{2}$ Department of Physics, Faculty of Science, Sana'a University, Sana'a, Yemen \\ ${ }^{3}$ Department of Physics, Thamar University, Thamar, Yemen
}

Correspondence should be addressed to Bandar Ali Al-Asbahi; alasbahibandar@gmail.com and Mohammad Hafizuddin Haji Jumali; hafizhj@ukm.my

Received 23 January 2014; Accepted 16 April 2014; Published 7 May 2014

Academic Editor: Tianxi Liu

Copyright @ 2014 Bandar Ali Al-Asbahi et al. This is an open access article distributed under the Creative Commons Attribution License, which permits unrestricted use, distribution, and reproduction in any medium, provided the original work is properly cited.

The optical properties and charge transfer mechanism of poly $\left(9,9^{\prime}\right.$-di-n-octylfluorenyl-2.7-diyl) (PFO)/ZnO thin films have been investigated. The $\mathrm{ZnO}$ nanorods (NRs) were prepared via a microwave technique. The solution blending method was used to prepare the $\mathrm{PFO} / \mathrm{ZnO}$ nanocomposites. X-ray diffraction (XRD) and field emission scanning electron microscope (FE-SEM) were used to determine the structural properties, while UV-Vis and photoluminescence (PL) were employed to investigate the optical properties of the films. XRD patterns confirmed that there was no variation in the structure of both PFO and $\mathrm{ZnO}$ NRs due to the blending process. FE-SEM micrographs displayed that ZnO NRs were well coated by PFO in all nanocomposite films. The absorption spectra of the nanocomposite thin films exhibited a red-shift indicating the increment in conjugation length of the $\mathrm{PFO} / \mathrm{ZnO}$ nanocomposite. Significant quenching in the emission intensity of PFO was observed in fluorescence spectra of the nanocomposite films. This quenching was attributed to efficient charge transfer in the $\mathrm{PFO} / \mathrm{ZnO}$ nanocomposites, which was further supported by the shorter PL lifetime of PFO/ZnO than that of the PFO thin film. The continuous decline in PL intensity of these nanocomposites is attributed to homogenous dynamic quenching between PFO and $\mathrm{ZnO}$ NRs.

\section{Introduction}

The growing interest in polymer based photoelectric devices, in particular conjugated polymer, can be attributed to several factors such as environmentally friendly, adjustable band gaps, high optical absorption coefficient, and low-cost fabrication. All of these factors can be achieved because of the flexibility in organic synthesis; hence, the chemical tailoring towards the desired properties is possible. For example, poly(3-hexylthiophene) and poly(p-phenylene vinylene) and their derivatives have been reported to absorb light at various wavelengths $[1,2]$.

There are great concerns about the photo stability and thermal stability of the polymers, although other pressing problems are associated with polymer based photoelectric devices which are poor electron-hole separation and transport properties $[3,4]$. While the former concern may be overcome by introducing a more stable polymer, the later problems are more challenging. Several approaches have been suggested to inhibit these problems [5-7], but a well accepted strategy is via hybridization with inorganic semiconducting nanostructures such as metal oxides [8-11]. Successful initial attempts motivate researchers to look for the right combination between a stable polymer and metal oxide and thus their optimum ratio.

In terms of stable polymers, there are a limited number of suitable candidates and one of them is poly $\left[9,9^{\prime}\right.$-di-noctylfluorenyl-2.7-diyl] (PFO). Earlier work reported that PFO displayed better photo stability and thermal stability than those of the poly(phenylene vinylene)s "PPVs" [12], 
which are commonly studied. PFO is a semicrystalline conjugated polymer [13-15] with lowest unoccupied molecular orbital (LUMO) and highest occupied molecular orbital (HUMO) of -2.9 and $-5.9 \mathrm{eV}$, respectively [16].

As one of the most widely investigated materials, $\mathrm{ZnO}$ is commonly used as electron acceptor in polymer/inorganic nanocomposites [17-20]. This metal oxide exhibits greater tendency to stabilize in wurtzite hexagonal form with conduction band, valence band, and energy gap of $-4.2,-7.6$, and $3.4 \mathrm{eV}$, respectively [18]. Most of the earlier works on polymer/ZnO nanocomposites demonstrated the photoluminescence (PL) quenching which was conveniently claimed due to efficient charge transfer effect [17-19].

One of the prerequisites for good photoelectric materials is efficient charge transfer, which in turn depends on the comparable band structures. Benefitting from quantum confinement effect with close consideration on suitability between the band structures, the combination between a more stable PFO and $\mathrm{ZnO}$ nanorods (NRs) is believed to result in better materials characteristics for photoelectric application. A common indicator for charge transfer is PL emission quenching. Unfortunately, observation in PL quenching alone is not sufficient to suggest efficient charge transfer. Additional evidence via measuring the fluorescence lifetime is required. However, theoretical approach via calculating fluorescence lifetime [21] is conveniently used as an alternative method especially for researchers having limited equipment at their disposal. The current work is not only calculated fluorescence lifetime, but also other important parameters, namely, the quenching rate constant [22] and photo-induced electron transfer rate [23], which are used together as supplementary evidence to indicate tendencies of determined systems.

Evidence for charge transfer in $\mathrm{PFO} / \mathrm{ZnO}$ nanocomposites primarily from PL quenching was demonstrated in this work. In addition, values for the aforementioned parameters in case of dry thin films at room temperature were calculated to provide additional evidence for the effective charge transfers. The quenching type and quenching efficiency were also determined in order to have more comprehensive information on the suitability of this nanocomposite as an active layer in the photoelectric devices.

\section{Experimental Details}

$\mathrm{ZnO}$ NRs were synthesized using the microwave technique. A microwave oven (Sanyo Electric model no. EM-G430, $2.45 \mathrm{GHz}, 1000 \mathrm{~W}$ ) was used in this work. Deionized water (resistivity $18.2 \mathrm{M} \Omega \cdot \mathrm{cm}$ ) was used to prepare zinc acetate dihydrate $0.15 \mathrm{M}\left(\mathrm{C}_{4} \mathrm{H}_{6} \mathrm{O}_{4} \mathrm{Zn} \cdot 2 \mathrm{H}_{2} \mathrm{O}\right)$ (Aldrich, Fluka) aqueous solution (A) and $3.33 \mathrm{M}$ of $\mathrm{NaOH}$ aqueous solution (B) at room temperature. The zinc acetate aqueous solution (A) was stirred for $5 \mathrm{~min}$ and then the aqueous solution (B) was added dropwise under steady stirring until a white solution was formed. Then, the final white solution was exposed to microwave radiation in the oven for $5 \mathrm{~min}$ before being left to cool naturally to $30^{\circ} \mathrm{C}$. Subsequently, the solution was centrifuged at $4000 \mathrm{rpm}$ for $5 \mathrm{~min}$ to collect the white precipitate produced after radiation. The precipitate was washed with alcohol and deionized water alternately for four times and then was dried under atmosphere at $60^{\circ} \mathrm{C}$ for $24 \mathrm{~h}$. Finally, the obtained powder was heated at $500^{\circ} \mathrm{C}$ for $2 \mathrm{~h}$ in a conventional oven.

The PFO (product from Sigma Aldrich, USA) with average molecular weight of 58.200 was used in this study. To prepare the nanocomposites, firstly, the PFO was dissolved in tetrahydrofuran (THF) at a concentration of $3.0 \mathrm{mg} / \mathrm{mL}$ (PFO/THF). The PFO/ZnO nanocomposites were prepared in solution form by blending the fixed concentration of $\mathrm{ZnO}$ $(3.0 \mathrm{mg} / \mathrm{mL})$ with various ratios of PFO $(0,10,30,50$, and 70 wt.\%) followed by sonication for $5 \mathrm{~min}$. Then, the solution was deposited onto a glass substrate $(1.2 \mathrm{~cm} \times 2 \mathrm{~cm})$ to form three layers by a spin coating technique (rotational speed of $2000 \mathrm{rpm}$ for $30 \mathrm{~s}$ ). Finally, it was left to dry at room temperature.

The structural characterization of the films was carried out by X-ray diffraction (Bruker-AXS D8 Advance X-ray diffractometer using $\mathrm{Cu}-\mathrm{K} \alpha$ radiation source with $\lambda=$ $1.5418 \AA$ ). The nanostructure of the films was observed using a field emission scanning electron microscope (FE-SEM) model Supra 55VP with operating voltage of $3.00 \mathrm{kV}$. The absorption and emission spectra of the films were recorded using UV-Vis spectrophotometer (Perkin Elmer LAMBDA 900) and Luminescence spectrometer (Perkin Elmer LS55), respectively.

\section{Results and Discussion}

The X-ray diffractograms for the $\mathrm{ZnO} \mathrm{NRs}, \mathrm{PFO}$, and $\mathrm{PFO} / \mathrm{ZnO}$ nanocomposite thin films are shown in Figure 1. The diffractogram of $\mathrm{ZnO}$ NRs shows that all peaks can be indexed to the wurtzite hexagonal structure of $\mathrm{ZnO}$ crystal and no other crystalline peaks of any impurities were detected (Figure 1(a)). By comparison, the XRD diffractograms for PFO consist of a narrow peak at $7^{\circ}$ and broad peaks in between $10^{\circ}$ and $30^{\circ}(2 \theta)$, which can be deconvoluted into three broad peaks at $15.5^{\circ}, 20.0^{\circ}$, and $23.1^{\circ}$. This observation confirmed that the PFO is in semicrystalline phase as suggested by earlier reports [13-15]. The X-ray diffractograms for nanocomposite thin films consist of broad PFO peaks with several narrow peaks representing $\mathrm{ZnO}$ NRs. The intensities of $\mathrm{ZnO}$ NRs peaks in these nanocomposite films are enhanced as more $\mathrm{ZnO}$ NRs are added into the polymer (Figure 1(c)). More importantly, the structure of both PFO and $\mathrm{ZnO}$ NRs remained unchanged even after the blending process.

Figure 2 displays the morphology of $\mathrm{ZnO} \mathrm{NRs}$ and $\mathrm{PFO} / \mathrm{ZnO}$ nanocomposites. The $\mathrm{ZnO}$ existed as wurtzite hexagonal nanorods (pencil-like) having an average diameter of about $95 \mathrm{~nm}$ and length of $800 \mathrm{~nm}$ (Figure 2(a)). The nanorods were closely packed which were grown from a common seed. The smooth hexagonal structures of the $\mathrm{ZnO}$ NRs confirm that the nanorods were well crystalline as wurtzite unit cell.

The general view of nanocomposite film (Figure 2(b)) reveals the uniformity of the deposited film. A closer view of 


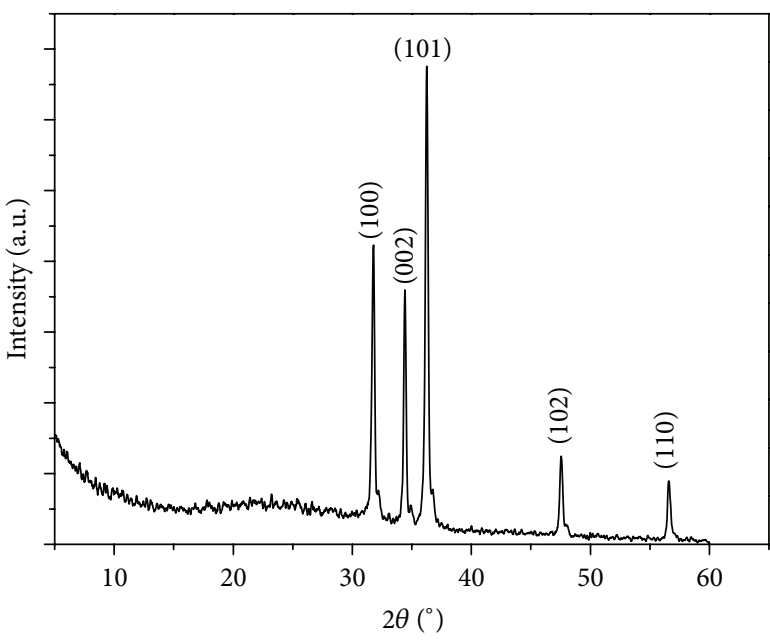

(a)

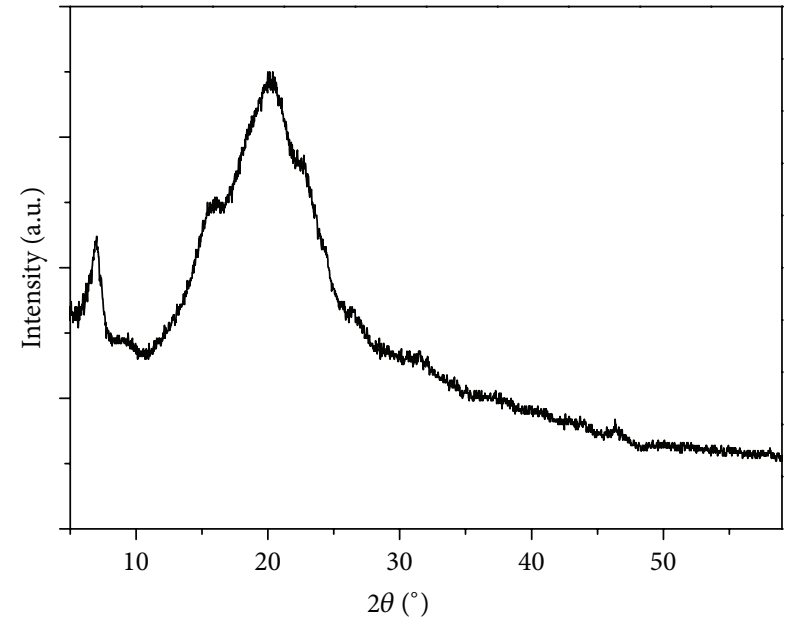

(b)

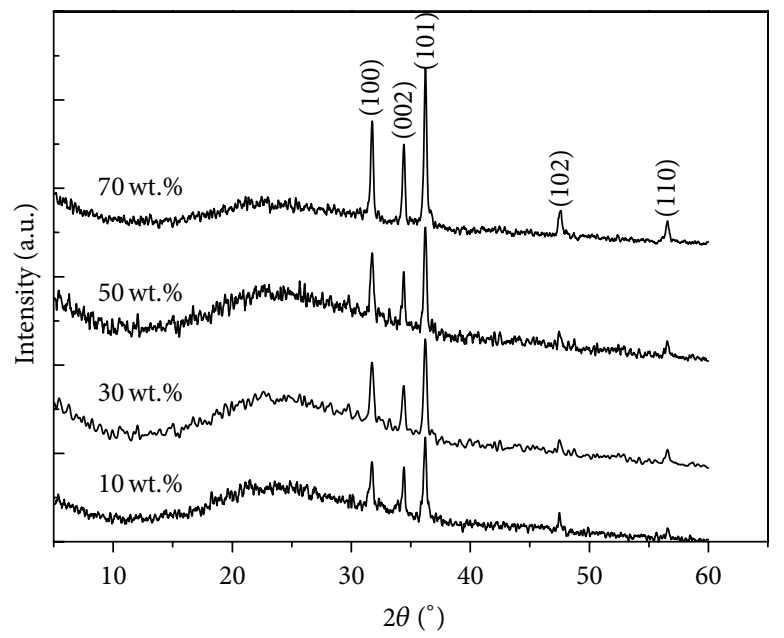

(c)

Figure 1: XRD patterns of (a) ZnO NRs, (b) pure PFO, and (c) PFO/ZnO nanocomposite films.

the films showed that the majority of $\mathrm{ZnO}$ NRs were broken into smaller rods and covered by PFO in all nanocomposites thin films (Figures 2(c)-2(f)). At $10 \mathrm{wt} . \% \mathrm{ZnO} \mathrm{NRs}$, all nanorods were covered and uniformly distributed. As the $\mathrm{ZnO}$ NRs content increased, the nanorods were thinly coated by the PFO. At 70 wt.\%, there were many uncoated nanorod bundles, which are believed to be due to the lack of PFO.

The absorption spectra of all films were presented in Figure 3. The UV-Vis spectrum of PFO film displays a $\lambda_{\max }$ at $404 \mathrm{~nm}$ which corresponds to a $\Pi-\Pi^{*}$ transition [24] and a shoulder around $435 \mathrm{~nm}$ as the fingerprint for $\beta$-phase of PFO [25]. By comparison, the absorption edge of $\mathrm{ZnO}$ NRs was located in the UV region $(<360 \mathrm{~nm})$, which is similar to an earlier report [21]. Upon addition of $\mathrm{ZnO} \mathrm{NRs}$, the absorbance of the nanocomposite films was dramatically reduced. No additional absorption peak was observed in the spectra confirming the absence of interaction between PFO and $\mathrm{ZnO}$ NRs at the ground states [19].

Relative to pure PFO, all absorption peaks of $\mathrm{PFO} / \mathrm{ZnO}$ nanocomposite thin films were red-shifted (around $11 \mathrm{~nm}$ ) signifying the extension in the conjugation length of the nanocomposites [26-28].

Figure 4 shows the fluorescence spectra of $\mathrm{ZnO}$ NRs, pure $\mathrm{PFO}$, and $\mathrm{PFO} / \mathrm{ZnO}$ nanocomposite thin films with various $\mathrm{ZnO}$ contents. The UV emission in the fluorescence spectrum of $\mathrm{ZnO}$ NRs (Figure 4(a)) comprises two overlapping bands. The peak of the first band centered at $378 \mathrm{~nm}$, which is related to the near-band edge emission of the wide band gap $\mathrm{ZnO}$ NRs. This band was due to the recombination of excitonic centres in the nanorod [29]. Additionally, a broad green band at $460-550 \mathrm{~nm}$ was observed, which is mainly caused by the intrinsic defects or oxygen vacancies in the $\mathrm{ZnO} \mathrm{NRs}$ and results in the recombination of a photo-generated hole with the single ionized charge state of this defect $[21,30]$.

Figure 4(b) reveals the emission peaks of $\mathrm{PFO}$ at 427, 442, 465 , and $500 \mathrm{~nm}$, which were assigned to $0-0,0-1,0-2$, and $0-$ 3 vibronic transition, respectively. As in absorption spectra, addition of $\mathrm{ZnO}$ NRs resulted in red-shift of the emission peaks position. More importantly, a dramatic quenching of PFO emission intensity was observed, and above $30 \mathrm{wt} \%$ of 


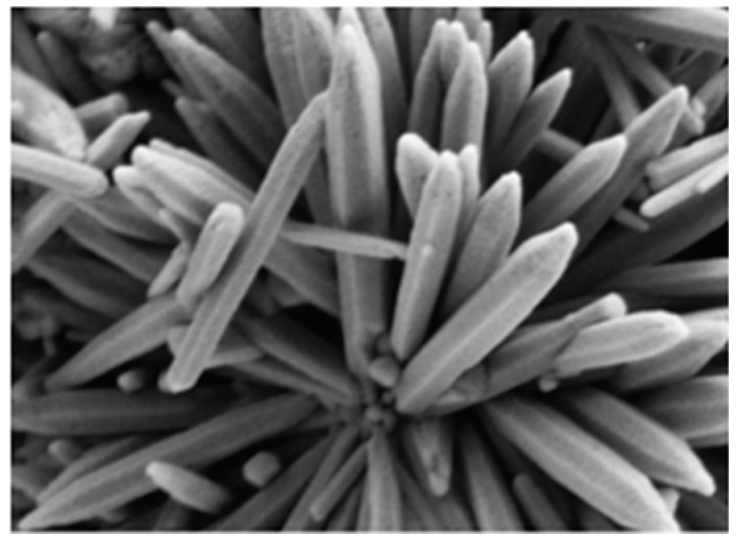

$100 \mathrm{~nm}$

(a)

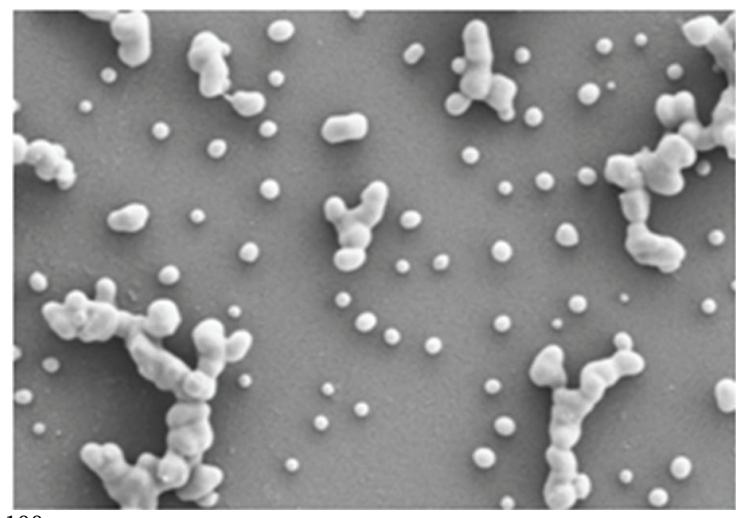
$100 \mathrm{~nm}$

(c)

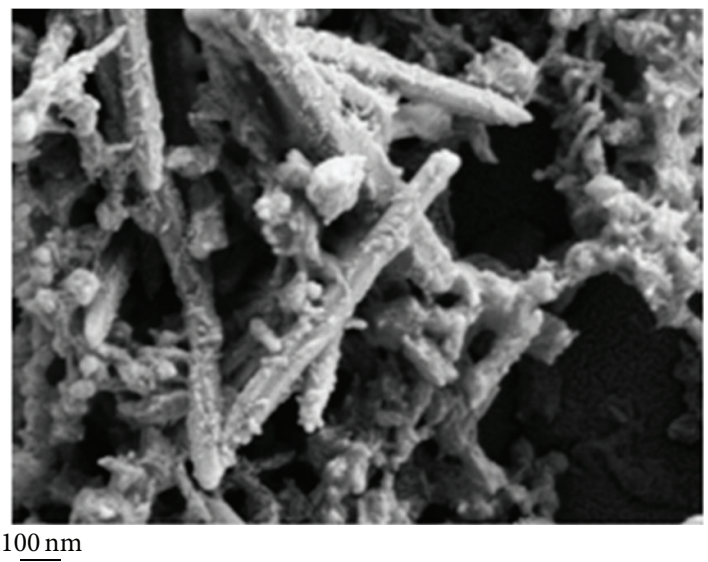

(e)

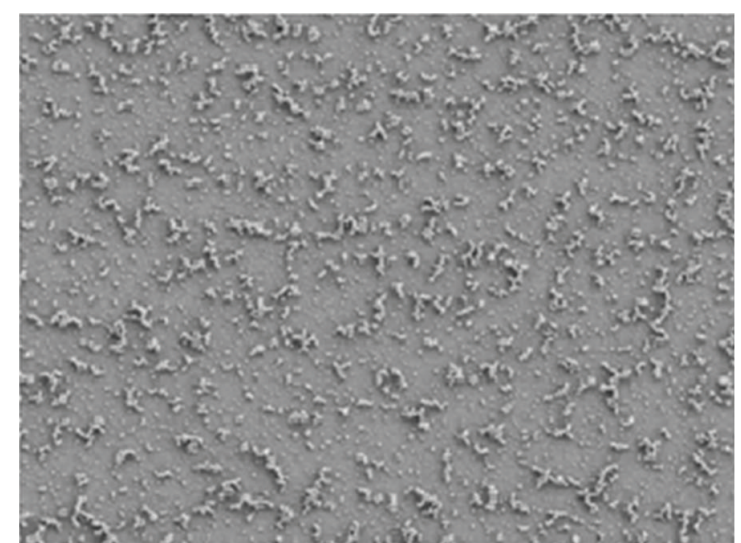

$2 \mu \mathrm{m}$

(b)

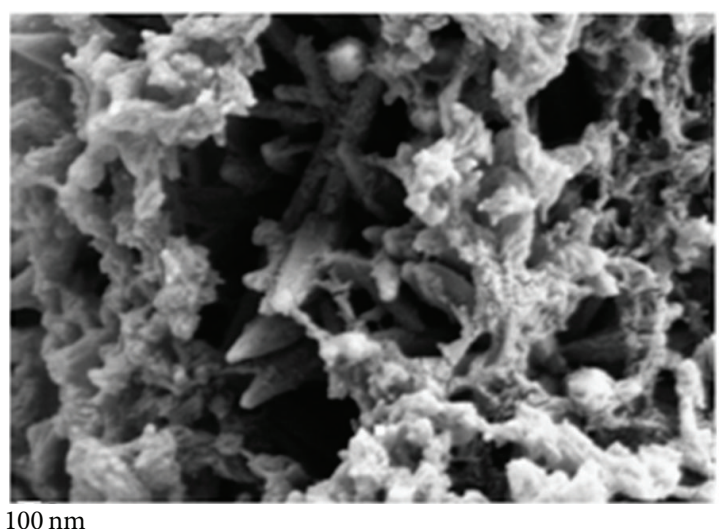

(d)

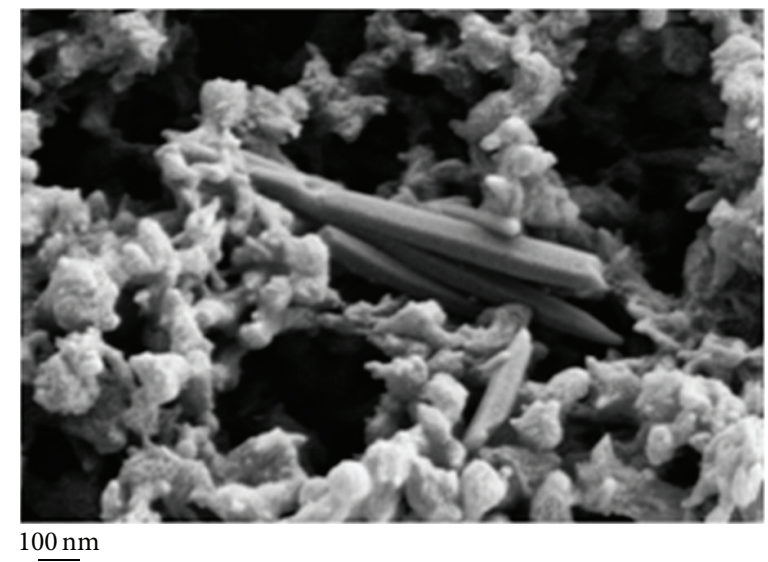

(f)

FIGURE 2: FE-SEM images of ZnO NRs and PFO/ZnO nanocomposites: (a) ZnO NRs, (b) distribution of PFO/ZnO nanocomposite on thin film at $90: 10 \mathrm{wt} . \%$, (c) $90: 10 \mathrm{wt} . \%$, (d) $70: 30 \mathrm{wt} . \%$, (e) $50: 50 \mathrm{wt} . \%$, and (f) $30: 70 \mathrm{wt} . \%$ nanocomposite thin films.

$\mathrm{ZnO}$ NRs content, the $427 \mathrm{~nm}$ peak of pure PFO completely disappeared.

Since there was no overlap between the emission spectrum of PFO (Figure 4(b)) and the absorption spectrum of $\mathrm{ZnO}$ NRs (Figure 3(a)), dramatic PL quenching in PFO in the hybrid system was due to charge transfer from the polymer to the metal oxide NRs [31]. Due to the presence of
$\mathrm{ZnO}$ NRs, recombination of exciton in PFO was inhibited. Instead, the electron-hole pairs in the polymer dissociated at the $\mathrm{PFO} / \mathrm{ZnO}$ interface with the electrons moving across the interface into $\mathrm{ZnO}$ NRs while the holes remain in the PFO.

This argument is supported by the fact that the conduction and valence bands of $\mathrm{ZnO}$ are relatively lower than those of PFO. Therefore, from an energy level point of 


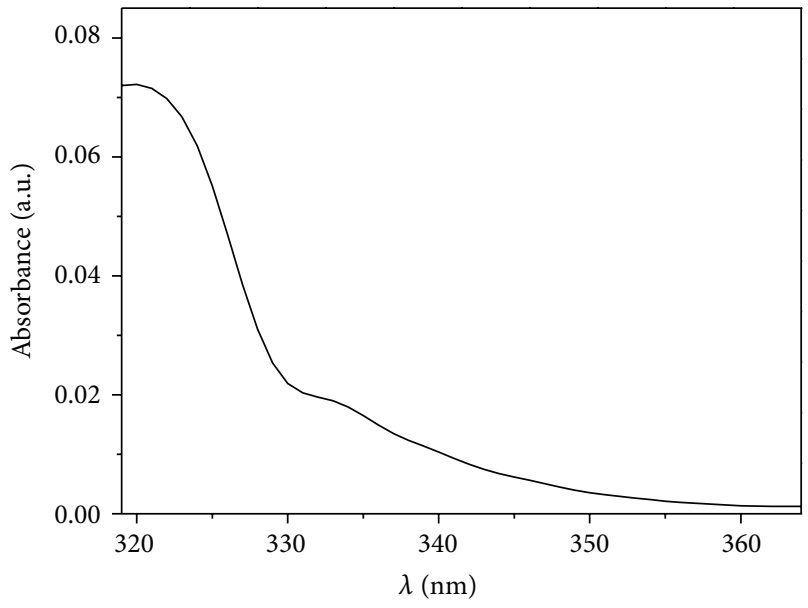

(a)

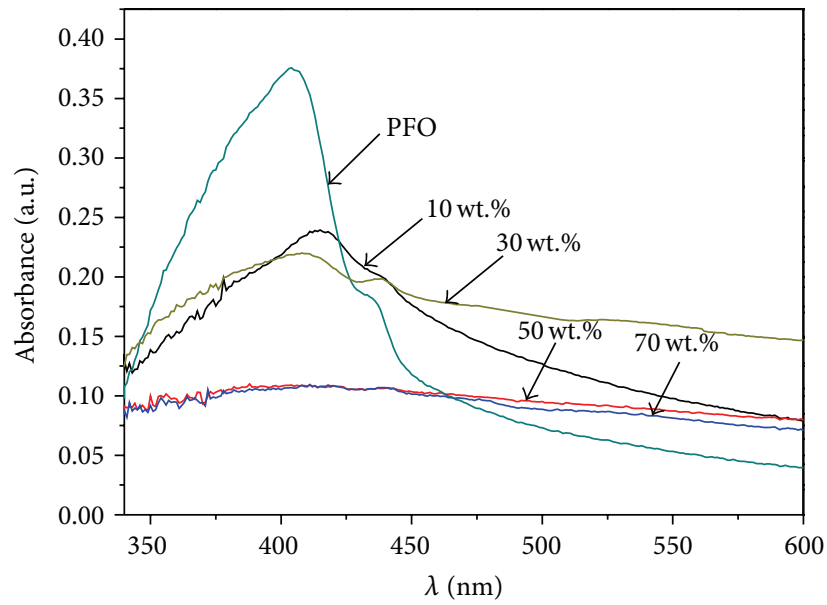

(b)

Figure 3: Absorption spectra of PFO/ZnO nanocomposite films.

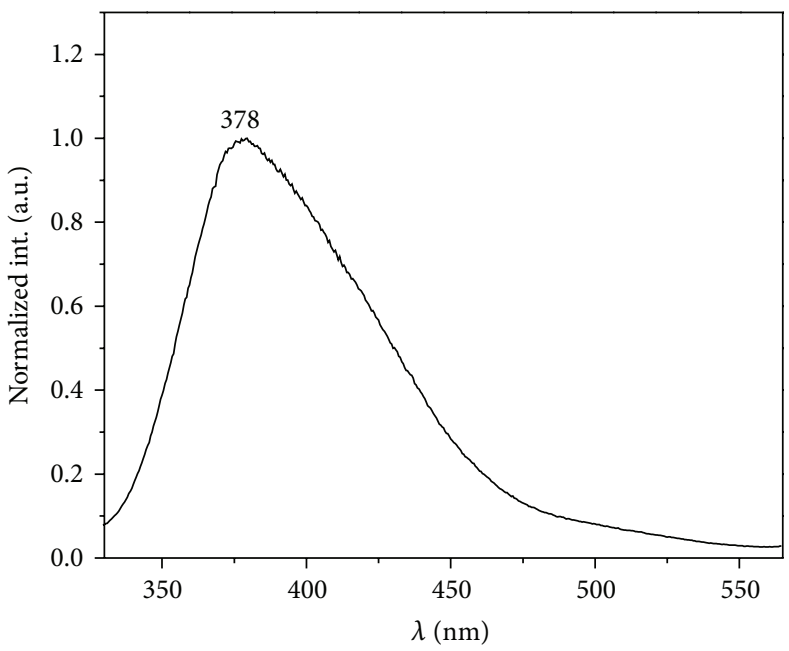

(a)

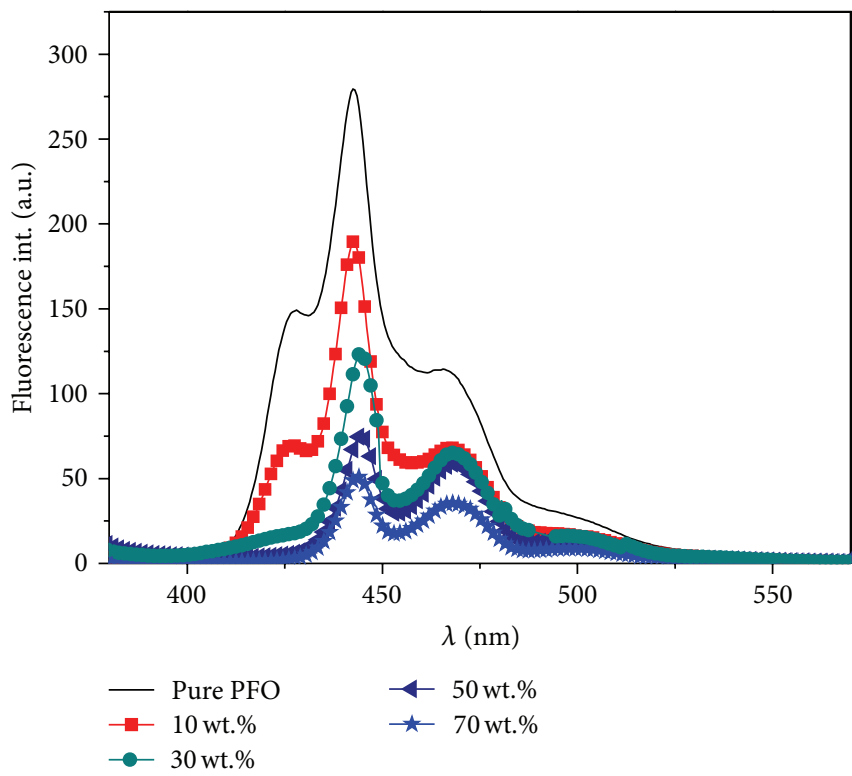

(b)

FIGURE 4: Fluorescence spectra of (a) pure ZnO NRs, excitation at $320 \mathrm{~nm}$, and (b) pure PFO and PFO/ZnO nanocomposite films, excitation at $355 \mathrm{~nm}$.

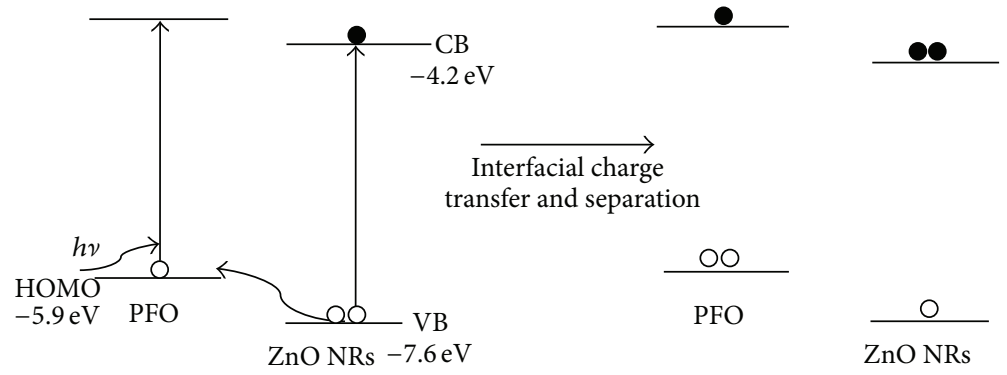

FIGURE 5: The interfacial charge generation, transfer, and separation between PFO and ZnO NRs. (Open circle: hole; closed circle: electron). 


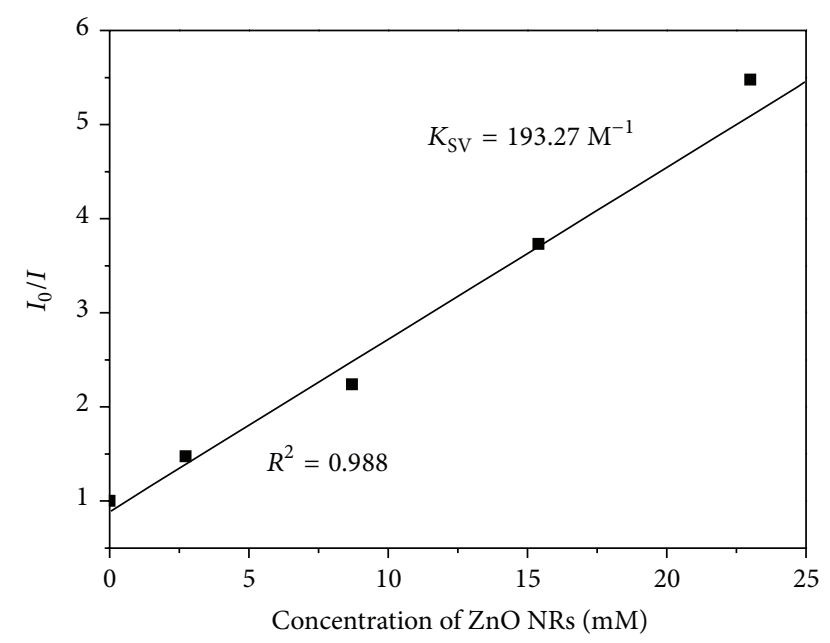

FIGURE 6: Stern-Volmer plot for fluorescence quenching of $3 \mathrm{mg} / \mathrm{mL}$ (PFO) by $\mathrm{ZnO}$ NRs.

view, the effective transfer of electron across the interface is possible (Figure 5). The dissociation of electron-hole pairs at interface and subsequent efficient electrons transfer to $\mathrm{ZnO}$ NRs suggested that the $\mathrm{PFO} / \mathrm{ZnO}$ nanocomposite is a promising $\mathrm{p}$-n-type nanocomposite material.

Effective charge transfer between $\mathrm{PFO}$ and $\mathrm{ZnO}$ NRs can be further confirmed from important parameters such as quenching rate constant $\left(K_{\mathrm{SV}}\right)$, lifetime $(\tau)$ of excited $\mathrm{PFO}$ in the presence of $\mathrm{ZnO} N R s$, bimolecular quenching rate $\left(k_{q}\right)$, and photo-induced electron transfer rate $\left(K_{\mathrm{ET}}\right) . K_{\mathrm{SV}}$ is the value of the slope in Stern-Volmer plot. The $\tau, k_{q}$, and $K_{\mathrm{ET}}$ can be calculated once the $K_{\mathrm{SV}}$ value is obtained.

Utilizing Stern-Volmer relationship [22], a linear SternVolmer plot with $R^{2}=0.988$ can be drawn and presented in Figure 6 . The linear relationship is a very important indicator of homogenous dynamic quenching of this hybrid material. The slop of the plot was $\sim 193.27 \mathrm{M}^{-1}$, which was comparable with $\mathrm{MEH}-\mathrm{PPV} / \mathrm{TiO}_{2}$ nanocomposite material [31]. This $K_{\mathrm{SV}}$ value signified that $50 \%$ of the PFO emission quenched at $\mathrm{ZnO}$ NRs concentration of $5.2 \mathrm{mM}$.

In homogeneous dynamic quenching, the Stern-Volmer equation can be rewritten as [22]

$$
\frac{\tau_{0}}{\tau}=1+K_{\mathrm{SV}}[Q]
$$

where $\tau$ and $\tau_{0}$ are the excited state lifetime of PFO in the presence and absence of $\mathrm{ZnO}$ NRs, respectively, and [Q] is the concentration of $\mathrm{ZnO}$ NRs.

Table 1 shows the effect of quencher (ZnONRs) on the photoluminescence lifetime of PFO. All nanocomposite materials exhibited shorter lifetime than the pristine PFO thin film, $\tau_{0}=0.346 \mathrm{~ns}$ [32] confirming the efficient charge transfer from $\mathrm{PFO}$ to $\mathrm{ZnO} \mathrm{NRs}$ at the interfaces [21]. Furthermore, compatible band structure between both materials induced the electron transfer from LUMO of PFO to $\mathrm{CB}$ of $\mathrm{ZnO}$ (Figure 5).
The bimolecular quenching rate $\left(k_{q}\right)$ and the photoinduced electron transfer rate $\left(K_{\mathrm{ET}}\right)$ for $\mathrm{PFO} / \mathrm{ZnO}$ nanocomposite films can be calculated using (2) [33] and (3) [34] as follows:

$$
\begin{aligned}
& K_{\mathrm{SV}}=\tau_{0} k_{q} \\
& K_{\mathrm{ET}}=\frac{1}{\tau}-\frac{1}{\tau_{0}} .
\end{aligned}
$$

Using (2), the $k_{q}$ has been evaluated as $5.59 \times 10^{11} \mathrm{M}^{-1} \cdot \mathrm{S}^{-1}$. This value is significantly greater than the minimum value for efficient quenching, which is $1 \times 10^{10} \mathrm{M}^{-1} \cdot \mathrm{S}^{-1}$ [22]. The high value of $k_{q}$ obtained in this work proves the good combination between the $\mathrm{ZnO}$ NRs and PFO. Equally important, high $k_{q}$ value signified the admirable quality of the interface between these two materials. The values of $k_{\mathrm{ET}}$ calculated using (3) were constantly increased from $1.53 \times 10^{9}$ to $12.73 \times$ $10^{9} \mathrm{~S}^{-1}$ as more $\mathrm{ZnO}$ NRs are added into PFO (Table 1). This finding provides additional evidence illustrating significant improvement in quenching efficiency and charge transfer in $\mathrm{PFO} / \mathrm{ZnO}$ nanocomposite upon increment of $\mathrm{ZnO}$ NRs. The calculated $k_{\mathrm{ET}}$ values in this work are comparable with other organic-metal oxide nanocomposite systems such as phycocyanin $/ \mathrm{TiO}_{2}$ [23]. In other words, the photo-induced electron transfer rate from $\mathrm{PFO}$ monomers to $\mathrm{ZnO}$ NRs can be controlled with the $\mathrm{ZnO}$ NRs content. High ZnO NRs content has a high surface area, which gives an increase to a lot of defects and raises the electron transfer rate. Consequently, more efficient $\mathrm{PFO} / \mathrm{ZnO}$ nanocomposite can be obtained as an active layer in photoelectric devices.

\section{Conclusion}

This work reports on the study of charge transfer mechanism in $\mathrm{PFO} / \mathrm{ZnO}$ nanocomposite thin films. $\mathrm{ZnO}$ NRs were successfully synthesized using the microwave technique, whereas $\mathrm{PFO} / \mathrm{ZnO}$ nanocomposites were successfully prepared via solution blending method prior to producing the films using spin coating technique. The X-ray diffractograms confirmed the purity of $\mathrm{ZnO} \mathrm{NRs}$ and the existence of amorphous phase of PFO and crystalline phase of $\mathrm{ZnO}$ NRs. As the $\mathrm{ZnO}$ NRs content increased, the emission intensity of PFO reduced suggesting enhanced quenching fluorescence of PFO. The quenching rate $\left(K_{\mathrm{SV}}\right)$ and the bimolecular quenching rate $\left(K_{q}\right)$ constants were estimated to be about $193.27 \mathrm{M}^{-1}$ and $5.59 \times 10^{11} \mathrm{M}^{-1} \cdot \mathrm{S}^{-1}$, respectively. In addition, as the $\mathrm{ZnO}$ NRs content increased from 10 to $70 \mathrm{wt} . \%$, the photo-induced electron transport rate increased from $1.53 \times 10^{9}$ to $12.73 \times$ $10^{9} \mathrm{~S}^{-1}$. Moreover, it was found that the photoluminescence lifetime for the $\mathrm{PFO} / \mathrm{ZnO}$ thin films is much shorter than that of the pure PFO thin film. These findings confirmed the efficient electron transfer across $\mathrm{PFO} / \mathrm{ZnO}$ interface, which are very crucial for greater improvement in the performance of the $\mathrm{PFO} / \mathrm{ZnO}$ based photoelectric devices. 
TABLE 1: Photo-induced electron transport rate and lifetime values of $\mathrm{PFO} / \mathrm{ZnO}$ nanocomposite thin films.

\begin{tabular}{|c|c|c|c|}
\hline $\begin{array}{l}\text { The weight ratio of } \mathrm{ZnO} \text { NRs } \\
\text { (wt.\%) }\end{array}$ & $\begin{array}{l}\text { Concentration of } \mathrm{ZnO} \text { NRs }[Q] \\
(\mathrm{mM})\end{array}$ & $\begin{array}{l}\text { Lifetime of PFO } \\
\tau(\mathrm{ns}) \\
\end{array}$ & $\begin{array}{l}\text { Photo-induced electron } \\
\text { transport rate } K_{\mathrm{ET}}\left(\mathrm{S}^{-1}\right) \times 10^{9}\end{array}$ \\
\hline 0 & 0 & 0.346 & - \\
\hline 10 & 2.73 & 0.226 & 1.53 \\
\hline 30 & 8.7 & 0.129 & 4.86 \\
\hline 50 & 15.4 & 0.087 & 8.60 \\
\hline 70 & 23.0 & 0.064 & 12.73 \\
\hline
\end{tabular}

\section{Conflict of Interests}

The authors declare that they have no conflict of interests regarding the publication of this paper.

\section{Acknowledgment}

The authors would like to thank the Universiti Kebangsaan Malaysia (UKM) for providing excellent research facilities, under the Research University Grants DPP-2013-048 and DLP-2013-012.

\section{References}

[1] F. Padinger, R. S. Rittberger, and N. S. Sariciftci, "Effects of postproduction treatment on plastic solar cells," Advanced Functional Materials, vol. 13, no. 1, pp. 85-88, 2003.

[2] Q. Zhou, Q. Hou, L. Zheng, X. Deng, G. Yu, and Y. Cao, "Fluorene-based low band-gap copolymers for high performance photovoltaic devices," Applied Physics Letters, vol. 84, no. 10, pp. 1653-1655, 2004.

[3] W. U. Huynh, J. J. Dittmer, and A. P. Alivisatos, "Hybrid nanorod-polymer solar cells," Science, vol. 295, no. 5564, pp. 2425-2427, 2002.

[4] D. Haarer, "Photoconductive polymers: structure, mechanisms, and properties," Die Angewandte Makromolekulare Chemie, vol. 183, no. 1, pp. 197-220, 1990.

[5] S. R. Forrest, "The road to high efficiency organic light emitting devices," Organic Electronics: Physics, Materials, Applications, vol. 4, no. 2-3, pp. 45-48, 2003.

[6] F. Li, Y. Du, Y. Chen, L. Chen, J. Zhao, and P. Wang, "Direct application of P3HT-DOPO@ZnO nanocomposites in hybrid bulk heterojunction solar cells via grafting $\mathrm{P} 3 \mathrm{HT}$ onto $\mathrm{ZnO}$ nanoparticles," Solar Energy Materials and Solar Cells, vol. 97, pp. 64-70, 2012.

[7] T. P. Nguyen, C. W. Lee, S. Hassen, and H. C. Le, "Hybrid nanocomposites for optical applications," Solid State Sciences, vol. 11, no. 10, pp. 1810-1814, 2009.

[8] J. K. Lee, W. L. Ma, C. J. Brabec et al., "Processing additives for improved efficiency from bulk heterojunction solar cells," Journal of the American Chemical Society, vol. 130, no. 11, pp. 3619-3623, 2008.

[9] A. J. Moulé and K. Meerholz, "Controlling morphology in polymer-fullerene mixtures," Advanced Materials, vol. 20, no. 2, pp. 240-245, 2008.

[10] N. Z. Yahya and M. Rusop, "Investigation on the optical and surface morphology of conjugated polymer MEH-PPV: $\mathrm{ZnO}$ nanocomposite thin films," Journal of Nanomaterials, vol. 2012, Article ID 793679, 4 pages, 2012.
[11] M. Alam, N. M. Alandis, A. A. Ansari, and M. R. Shaik, "Optical and electrical studies of polyaniline/ZnO nanocomposite," Journal of Nanomaterials, vol. 2013, Article ID 157810, 5 pages, 2013.

[12] A. M. Assaka, P. C. Rodrigues, A. R. M. de Oliveira et al., "Novel fluorine containing polyfluorenes with efficient blue electroluminescence," Polymer, vol. 45, no. 21, pp. 7071-7081, 2004.

[13] G. C. Farial, T. S. Plivelic, R. F. Cossiello et al., "A multitechnique study of structure and dynamics of polyfluorene cast films and the influence on their photoluminescence," Journal of Physical Chemistry B, vol. 113, no. 33, pp. 11403-11413, 2009.

[14] M. H. H. Jumali, B. A. Al-Asbahi, C. C. Yap, M. M. Salleh, and M. S. Alsalhi, "Optoelectronic property enhancement of conjugated polymer in poly $\left(9,9^{\prime}\right.$-di-n-octylfluorenyl-2.7-diyl)/titania nanocomposites," Thin Solid Films, vol. 524, pp. 257-262, 2012.

[15] M. H. H. Jumali, B. A. Al-Asbahi, C. C. Yap, M. M. Salleh, and M. S. Alsalhi, "Optical properties of poly $\left(9,9^{\prime}\right.$-di-n-octylfluorenyl2.7-diyl)/amorphous $\mathrm{SiO}_{2}$ nanocomposite thin films," Sains Malaysiana, vol. 42, no. 8, pp. 1151-1157, 2013.

[16] M. Bajpai, R. Srivastava, M. N. Kamalasanan, R. S. Tiwari, and S. Chand, "Charge transport and microstructure in PFO:MEHPPV polymer blend thin films," Synthetic Metals, vol. 160, no. 15-16, pp. 1740-1744, 2010.

[17] I. Park, Y. Lim, S. Noh et al., "Enhanced photovoltaic performance of $\mathrm{ZnO}$ nanoparticle/poly(phenylene vinylene) hybrid photovoltaic cells by semiconducting surfactant," Organic Electronics: Physics, Materials, Applications, vol. 12, no. 3, pp. 424428, 2011.

[18] L. Qian, Y. Zheng, K. R. Choudhury et al., "Electroluminescence from light-emitting polymer/ZnO nanoparticle heterojunctions at sub-bandgap voltages," Nano Today, vol. 5, no. 5, pp. 384-389, 2010.

[19] R. Jetson, K. Yin, K. Donovan, and Z. Zhu, "Effects of surface modification on the fluorescence properties of conjugated polymer/ZnO nanocomposites," Materials Chemistry and Physics, vol. 124, no. 1, pp. 417-421, 2010.

[20] K. Yuan, F. Li, L. Chen, and Y. Chen, "Approach to a block polymer precursor from poly(3-hexylthiophene) nitroxidemediated in situ polymerization for stabilization of poly(3hexylthiophene)/ZnO hybrid solar cells," Thin Solid Films, vol. 520, no. 19, pp. 6299-6306, 2012.

[21] Y. Y. Lin, C. W. Chen, W. C. Yen, W. F. Su, C. H. Ku, and J. $\mathrm{J}$. Wu, "Improved performance of polymer/ $/ \mathrm{TiO}_{2}$ nanorod bulk heterojunction photovoltaic devices by interface modification," Applied Physics Letters, vol. 92, no. 5, Article ID 053312, 4 pages, 2008.

[22] J. R. Lakowicz, Principles of Fluorescence Spectroscopy, Springer, New York, NY, USA, 3rd edition, 2008. 
[23] A. Kathiravan and R. Renganathan, "Photosensitization of colloidal $\mathrm{TiO}_{2}$ nanoparticles with phycocyanin pigment," Journal of Colloid and Interface Science, vol. 335, no. 2, pp. 196-202, 2009.

[24] Z. Han, J. Zhang, X. Yang, H. Zhu, and W. Cao, "Synthesis and application in solar cell of poly(3-octylthiophene)/titania nanotubes composite," Organic Electronics: Physics, Materials, Applications, vol. 11, no. 8, pp. 1449-1460, 2010.

[25] R. Palacios, P. Formentin, E. Martinez-Ferrero, J. Pallarès, and L. F. Marsal, " $\beta$-phase morphology in ordered poly $(9,9-$ dioctylfluorene) nanopillars by template wetting method," Nanoscale Research Letters, vol. 6, no. 1, pp. 1-5, 2011.

[26] G. Chen and P. Wang, "Alteration of the optical properties of poly $9,9^{\prime}$-dioctylfluorene by $\mathrm{TiO}_{2}$ nanocrystalline," Journal of Non-Crystalline Solids, vol. 352, no. 23-25, pp. 2536-2538, 2006.

[27] T. W. Hagler, K. Pakbaz, K. F. Voss, and A. J. Heeger, "Enhanced order and electronic delocalization in conjugated polymers oriented by gel processing in polyethylene," Physical Review B, vol. 44, no. 16, pp. 8652-8666, 1991.

[28] K. Pichler, D. A. Halliday, D. D. C. Bradley, P. L. Burn, R. H. Friend, and A. B. Holmes, "Optical spectroscopy of highly ordered poly(p-phenylene vinylene)," Journal of Physics: Condensed Matter, vol. 5, no. 38, pp. 7155-7172, 1993.

[29] M. H. Huang, Y. Wu, H. Feick, N. Tran, E. Weber, and P. Yang, "Catalytic growth of zinc oxide nanowires by vapor transport," Advanced Materials, vol. 13, no. 2, pp. 113-116, 2001.

[30] D. K. Bhat, "Facile synthesis of $\mathrm{ZnO}$ nanorods by microwave irradiation of zinc-hydrazine hydrate complex," Nanoscale Research Letters, vol. 3, no. 1, pp. 31-35, 2008.

[31] T. Vats, S. N. Sharma, M. Kumar et al., "Comparison of photostability, optical and structural properties of $\mathrm{TiO}_{2} /$ conjugated polymer hybrid composites prepared via different methods," Thin Solid Films, vol. 519, no. 3, pp. 1100-1105, 2010.

[32] B. A. Al-Asbahi, M. H. H. Jumali, C. C. Yap, M. H. Flaifel, and M. M. Salleh, "Photophysical properties and energy transfer mechanism of PFO/Fluorol 7GA hybrid thin films," Journal of Luminescence, vol. 142, pp. 57-65, 2013.

[33] F. Ricchelli, "Photophysical properties of porphyrins in biological membranes," Journal of Photochemistry and Photobiology B: Biology, vol. 29, no. 2-3, pp. 109-118, 1995.

[34] J. Zimmermann, J. von Gersdorff, H. Kurreck, and B. Röder, "Determination of the electron transfer parameters of a covalently linked porphyrin-quinone with mesogenic substituentsoptical spectroscopic studies in solution," Journal of Photochemistry and Photobiology B: Biology, vol. 40, no. 3, pp. 209-217, 1997. 

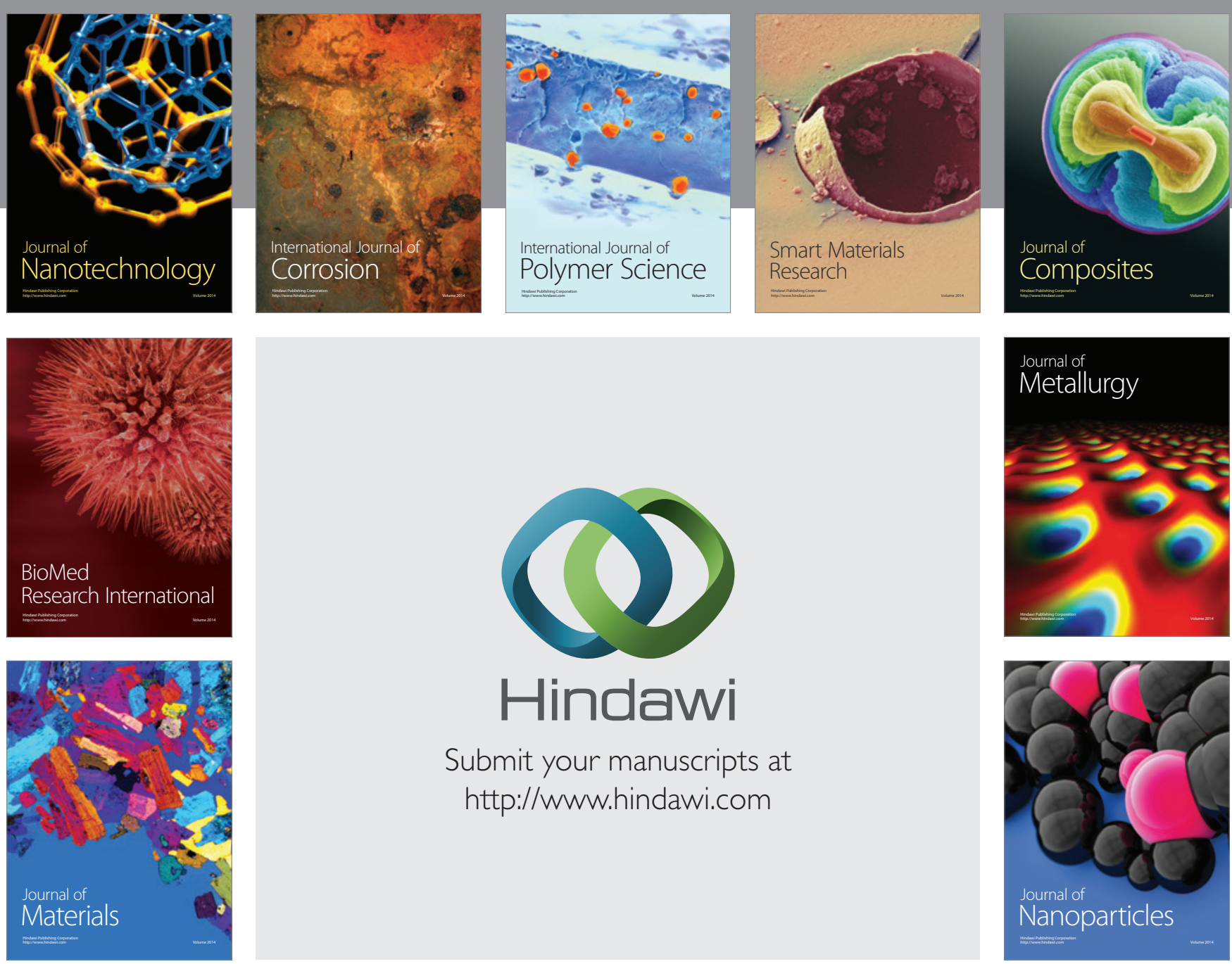

Submit your manuscripts at http://www.hindawi.com
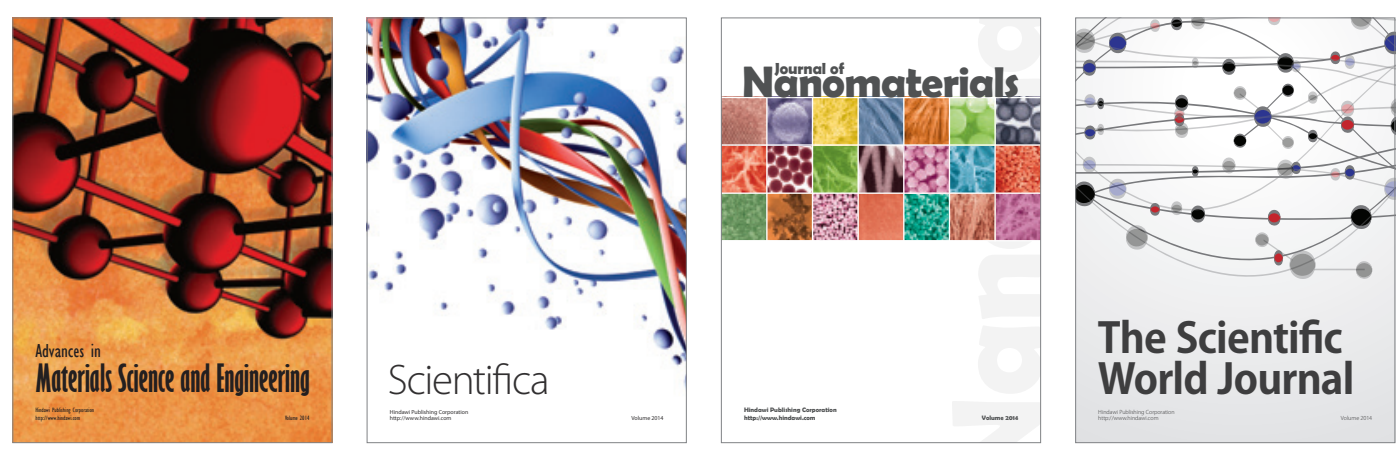

\section{The Scientific World Journal}
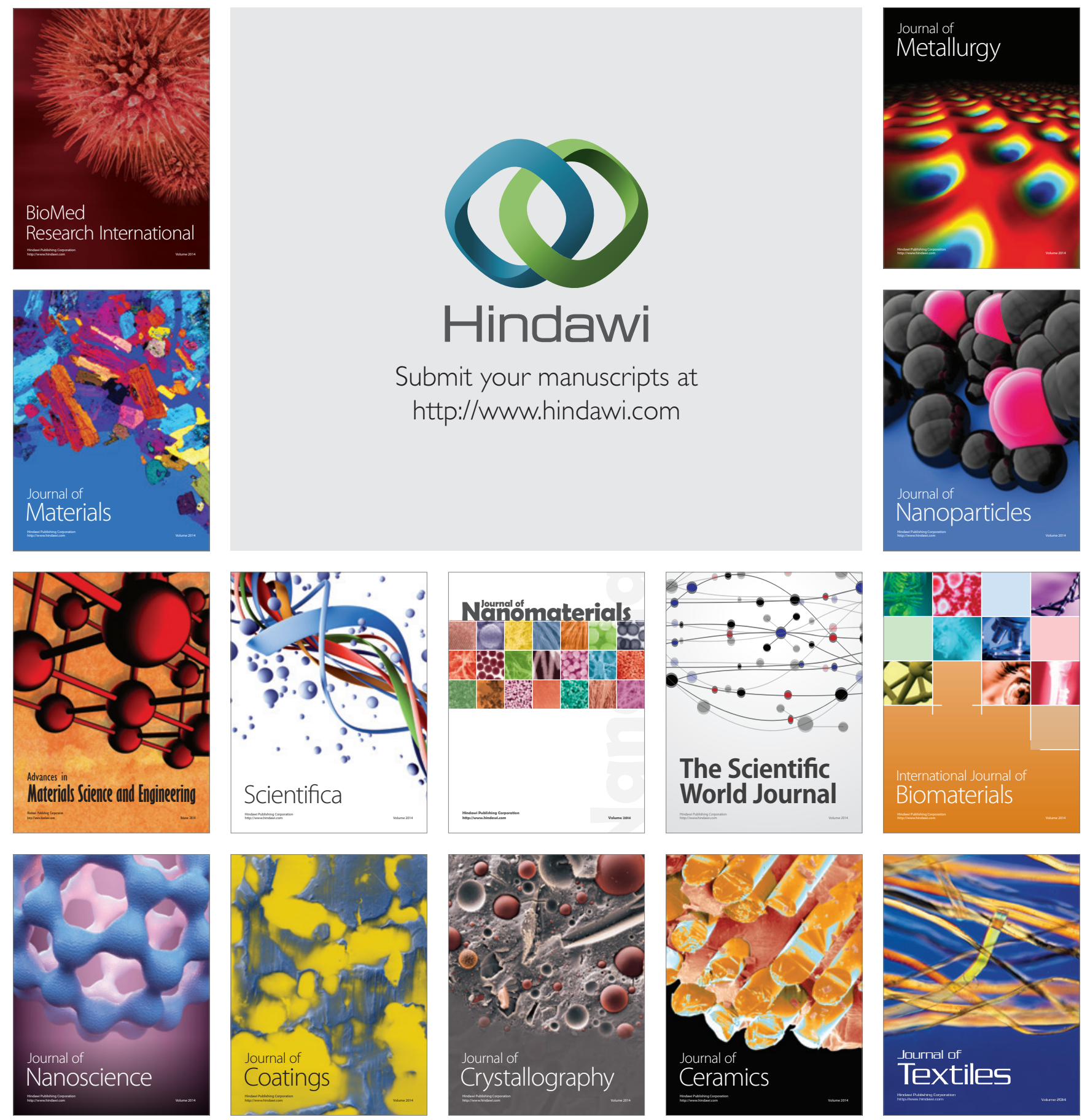